\section{Coping strategies and locus of control in childhood leukemia: a multi-center research}

\author{
Concetta Polizzi,1 Valentina Fontana,1 \\ Giovanna Perricone, ${ }^{1}$ Paolo D'Angelo,2 \\ Momcilo Jankovic,3 Calogero Taormina,2 \\ Francesca Nichelli, 3 Sofia Burgio 4 \\ 1Department of Psychological, Educational \\ and Training Sciences, University of \\ Palermo; 2Onco-Hematology Unit, \\ A.R.N.A.S. Civico-Di Cristina Benfratelli \\ Hospital of Palermo; 3Pediatric \\ Hematology Unit, San Gerardo Hospital, \\ Monza; ${ }^{4}$ Clinical Psychology of the Life \\ Span, University of Palermo, Italy
}

\section{Abstract}

Acute lymphoblastic leukemia (ALL) is a very distressing experience for children and requires a special effort of adjustment. Therefore, it seems to be crucial to explore coping resources for the experienced risk condition. In this sense, the study focuses on coping strategies and locus of control in children with ALL during the treatment phase, and on their possible relation. The correlation between children and maternal coping strategies is also investigated. The participants involved were an experimental group of 40 children with ALL and their mothers, and 30 healthy children as the control group. The tools used were: the Child Behavioral Style Scale and the Monitor-Blunter Style Scale to assess the coping strategies of children and mothers the locus of Control Scale for Children to analyze the children's perception of controlling the events. Both children with ALL and their mothers resorted to monitoring coping strategies with a statistically significant rate of occurrence (children: $\mathrm{M}=17.8, \mathrm{SD}=3.8$; mothers: $\mathrm{M}=10.48, \mathrm{SD}=3.4$ ). The data concerning the locus of control show this tendency towards internal causes $(\mathrm{M}=53.1, \mathrm{SD}=4.7)$. There were statistically significant correlations between monitoring coping strategies and external locus of control $(\mathrm{r}=0.400, \mathrm{P}<0.05)$. The results gained from the control group are almost equivalent. The outcomes show several interesting resources of the psychological functioning of children as well as of their mothers.

\section{Introduction}

Over recent years, a few studies have high- lighted that acute lymphoblastic leukemia (ALL) is a risk condition for the evolutional wellbeing of children since it might impair their development at physical, cognitive, behavioral and social level.1-7

However, the occurrence of malignant tumors in children/early adolescents (aged 014) has been at a steady stage for several years, despite the rise in diagnosis described over the $90 \mathrm{~s},{ }^{8}$ and the increasing number of children who survived tumor disease. Nevertheless, in 2008, in Italy cancer was still the major cause of death among children/early adolescents, and ALL was the most prevailing infantile cancer, with a higher incidence than in United States and North Europe. Every year, in Italy, 5 children among 100.000 suffer from leukemia, and 3 cases out of 4 are diagnosed as ALL. ${ }^{9}$ Suffering from tumors such as ALL and undergoing heavy necessary treatments turn out to be a very distressing and traumatic experience for children. ${ }^{3}$ Invasive and longlasting treatments cause physical pain and psychological suffering that alter children's daily life and the relationship with their body, as well as the self- and the others' image, and the connection between internal perception and external world.2,10-13

The marked change of children's everyday life requires an effort of adjustment, which is often really challenging, ${ }^{14}$ since the diagnosis, the hospitalization, the long-lasting treatment, and the frequent check-ups, as well as the way children value such stressors and what they are experiencing (the cancer and the treatment), may be extremely distressing. ${ }^{15}$

Children's anxiety coupled with parents' stress can make the whole family live a surrealistic experience. As a consequence, parents tend to consider the time and space of their own life exactly as if they were time and space of their children's, causing an alteration of their own skills of coping critical events and transforming the whole family's lifestyle as well. 3,4 The study is consistent with the latest literature of the field, that has focused on the complexity of the psychosocial adjustment of children with cancer and their respective parents, over the history of the disease, 5,16-18 identifying, especially during the treatment phase, children's tendency to use repressive coping strategies.7,19-21 It is noteworthy that this research project deals with some innovative and supplementary aspects that derive from the authors' interventions with children and families during the strenuous treatment phase. Firstly, the attribution of relevance to children's locus of control, 22 as a possible further internal resource for adjustment, as well as the interest in the likely relationship between such psychological characteristic and the coping strategies mostly used to face the difficulties during the treatment phase. Therefore, due to the difficulty of the adjust-
Correspondence: Concetta Polizzi, Department of Psychological, Educational and Training Sciences, University of Palermo, Viale delle Scienze, Ed. 15, 90128 Palermo, Italy.

Tel.: +39.091.23897740 - Fax: +39.091.6513825

E-mail: concetta.polizzi@unipa.it

Key words: Coping strategies; locus of control; leukemia; development.

Acknowledgments: we are grateful to all children and mothers who took part in the research project. Also we thank the medical and psychological team.

Contributions: CP, planning and design of research project, acquisition of data, statistical analysis, manuscript drafting; VF, planning of research project, acquisition of data, statistical analysis; GP, planning and design of research project, advises on analysis, manuscript drafting; PD, MJ, CT, FN, design of research project, acquisition of data; SB, acquisition and analysis of data; all authors approved the final paper.

Conflict of interests: the authors declare no potential conflict of interest.

Funding: the paper was funded by FFR project "Effetti psicoevolutivi a lungo termine del tumore diagnosticato nei primi anni di vita. Uno studio cross-culturale sui survivors e sui guariti", Department of Psychological, Educational and Training Sciences, University of Palermo, Italy.

Received for publication: 6 November 2014.

Revision received: 16 April 2015.

Accepted for publication: 18 April 2015.

This work is licensed under a Creative Commons Attribution NonCommercial 3.0 License (CC BYNC 3.0).

(C) Copyright C. Polizzi et al., 2015

Licensee PAGEPress, Italy

Pediatric Reports 2015; 7:5703

doi:10.4081/pr.2015.5703

ment process, as recognized by most studies of the field, $23-25$ it seems to be crucial to extend the research of specific children's psychological aptitudes that may be coping resources for the experienced risk condition. Equally crucial, it appears addressing the attention to caregivers' psychological functioning characteristics as likely children's external resource that can be useful for their psychosocial adjustment, and for preventing them from an evolutional black-out process.

From this point of view, the interest in the possible relationship between children's and maternal coping strategies - since mothers play a primary role as caregivers who accompany children over the whole history of disease should be considered as an additional fresh 
contribution of the study. The interest lies on the idea that, on their taking care of their respective children during almost all demanding stages of disease, mothers exhibit them behavioral models to face the difficulties that may influence the children's coping style.

\section{Materials and Methods}

On account of what said, the study focuses on coping efforts and locus of control. The interpreting model adopted read coping efforts in terms of style, cognitive, emotional and behavioral strategies useful for managing stressful occurrences. More specifically, it deals with the strategies effective to handle the history of disease that children suffering from leukemia, coupled with their respective mothers, activate within complex contexts and relationships during different phases of the natural progression of disease. The model considers the dichotomous coping styles, the pair of monitoring and blunting approaches, ${ }^{26}$ paying attention and being sensitive to every aspect of disease characterize the monitoring style, while distraction and cognitive avoidance of stressors delineate the blunting approach. The theoretic operational model adopted considers internal and external locus of control.22 Children may react either actively in order to control and face disease, or they have a passive response because they perceiving themselves as powerless against it. If children think that events occur because their own behavior provokes and control them, they will have internal locus of control; on the contrary, when they consider external environment, fate or the other's people control as the primary cause of events - which therefore they cannot control - they will have external locus of control. Based on the dichotomous coping approaches and the two kinds of locus of control as likely resources useful for the process of adjustment to disease during its natural progression, the study starts from some specific hypotheses. As for coping strategies, it hypothesizes that since children involved, with their respective mothers, have started the treatment phase - they are far off the challenging stress caused by the diagnosis and, therefore, they would mainly use monitoring coping strategies. The study also assumes the presence of a significant connection - in terms of modeling - between children's and mothers' coping strategies. Mothers who tend to mainly use active and adaptive coping strategies are coupled with children who choose monitoring strategies to face difficulties, as well as, mothers who adopt blunting coping strategies are connected to children who use escape coping. With regard to the relevance given by the study to locus of control, as mentioned in the introduction, it is hypothesized a connection between the coping styles mainly used by children to handle critical events, and their own attribution of sense and meaning to what happened (locus of control).

Such hypotheses considered, the goals of the study are: i) verify whether coping strategies of children with Leukemia are monitoring type; ii) verify the presence of a significant connection and its nature between coping strategies and the distinct causal attributions to critical events (LOC) made by children during the treatment phase; iii) verify the presence of a significant connection and its nature between the coping strategies activated by both children and mothers during the treatment phase.

\section{Participants}

The study involved one experimental group, which consisted of 40 children (15 males and 25 females) suffering from ALL ( $M=10.8$; $\mathrm{SD}=2.5$ ) who underwent the treatment phase two months past the diagnosis, and their respective mothers $(\mathrm{M}=41.7 ; \mathrm{SD}=6.3)$ (Table 1); one control group, consisted of 30 healthy children (11 females and 19 males) $(\mathrm{M}=10,4$; $\mathrm{SD}=2$ ), who where collected from a school in
Palermo. The two groups were symmetrical with regards to age, gender (percentage of males and females), families' socioeconomic status (defined according to parents' education), and nationality (Italian) (Table 1).

Since the study is a multicentric preliminary investigation, the experimental group recruitment involved two national centers of excellence of pediatric oncohematology that have had a research-based relationship for some years. Twenty-five children were recruited from the Hospital Unit of Pediatric Onco-hematology of A.R.N.A.S. Civico-Di CristinaBenfratelli of Palermo, while 15 children were selected from the Hospital Unit of Pediatric Hematology San Gerardo of Monza. The recruitment was carried out according to the following inclusion criteria: i) diagnosis of ALL; ii) time past from the diagnosis: about two months; iii) lack of severe neurologic sequelae and genetic syndromes; iv) children aged 8-13.

Even if the number of the participants was limited because of the recruitment criteria, it represented almost the entire universe of children with ALL who were hospitalized in Palermo and Monza at the time of the research (January-November 2013). The investigation was performed after the approval of Ethical Committee II of Palermo, and after acquiring the informed consent signed by both mothers and children. To be more precise, after the parents' approval, the researcher read and explained the children the form, which they were called on to sign, containing information about the study, the tools to be administered, and especially the advantages of participating. They were called on to participate in a path that would have enabled them to find out personal resources, powerful forces - e.g. the favorite way they were used to facing difficulties or self-explaining the events - as well as to be involved in guided activities of strengthening and support their likely weaknesses.

Table 1. Characteristics of experimental group (40 children and their mothers) and control group (30 children).

\begin{tabular}{|c|c|c|c|}
\hline Variables & Children experimental group & Children control group & Mothers experimental group \\
\hline Age, mean \pm SD & $10.8 \pm 2.5^{*}$ & $10.4 \pm 2 *$ & $41.7 \pm 6.3$ \\
\hline Time since diagnosis (days), mean \pm SD & $50.8 \pm 12.4$ & - & - \\
\hline Others diseases (allergies), yes/no & $7 / 33$ & $2 / 28$ & - \\
\hline $\begin{array}{l}\text { Gender } \\
\text { Male } \\
\text { Female }\end{array}$ & $\begin{array}{l}15(37.5 \%) \\
25(62.5 \%)\end{array}$ & $\begin{array}{l}11(37 \%) \\
19(63 \%)\end{array}$ & $\begin{array}{c}0 \\
40(100 \%)\end{array}$ \\
\hline $\begin{array}{l}\text { Title of study } \\
\text { Lower secondary education } \\
\text { High school } \\
\text { Degree }\end{array}$ & - & - & $\begin{array}{l}30 \% \\
50 \% \\
20 \%\end{array}$ \\
\hline Marital status, married & - & - & $40(100 \%)$ \\
\hline Household income & - & - & 1 \\
\hline
\end{tabular}




\section{Tools and procedures}

The research project administered the following investigation tools.

The Monitor-Blunter Style Scale (MBSS) was used to assess the coping strategies of the mothers of the children involved in the research project. ${ }^{27}$ It is a self-report situational anxiety questionnaire that presents four situations almost uncontrollable and distressing referring to near-real-life contexts such as a doctor's office, work environment, etc. Each situation has eight likely responses that the mother is asked to choose. The different coping styles are distinct in two halves: active behaviors such as, for example, asking for information (monitoring coping), and passive behaviors related to the choice of avoiding a situation perceived as adverse (blunting coping). The Child Behavioral Style Scale (CBSS) was used to evaluate children's coping strategies. ${ }^{20}$ It is the mirror version of MBSS where the uncontrollable and distressing situations regard children's contextual everyday life - for example at home, at school, at a dental office, etc. The difference from the version addressed to adults is that for each of the eight behaviors relating to a distressing situation, the children are call on to ask with a dichotomous YES/NO type response. As for the psychometrical properties, the tool has a good internal consistency. Dimensions referring to the blunting style are negatively correlated with the monitoring dimensions $\quad(\mathrm{r}=-0.41, \quad \mathrm{P}<0.01 ; \mathrm{r}=-0.49$, $\mathrm{P}<0.01)$. The test-retest shows that the subscales of the test are long-lasting stable $(\mathrm{r}=0.72, \mathrm{P}<0.01 ; \mathrm{r}=0.75, \mathrm{P}<0.01)$.

The Locus of Control Scale for Children was used to investigate the children's perception of controlling the events. ${ }^{28}$ It is a self-assessment scale consisted of 40 items, whose one half is related to internal cause attribution, while the other half to external attributions with a dichotomous model response YES/NO type. The items describe strengthening situations like foster caring, reaching goals, and becoming self-confident. As for the psychometrical properties the tool has a good internal consistence, which was measured through the splithalf method ( $r=0.63 ; r=0.68 ; r=0.74)$.

With regards to the administration procedure of the tools, the children and mothers are individually met at the Day Hospital or the hospital unit, after having first met a psychology of the pediatric oncohematology operational units, who explain each of them the meaning of the study, and give them the forms for the informed consent. The administration of the tools is performed in one meeting, followed by another one scheduled to talk about the inputs given by the tools.

\section{Analysis of data}

The collected data have been codified according to the procedures relevant to the tools used, and analyzed via descriptive and parametrical analysis, through the statistic software for Social Sciences SPSS (19.0 for Windows). The data were previously tested to verify the possible application of parametrical tests. The Kolmogorov-Smirnov's test has been used to verify the normality of the distribution of the coping strategies scores and the locus of control scores ( $\mathrm{P}>0.05)$, and the Levene's test has been used to verify the homogeneity of the variances between the groups $(\mathrm{P}>0.05)$.

Pearson's $r$ coefficient of correlation has been calculated, for the experimental group, to verify likely statistically significant correlations between the children's coping strategies and locus of control, and children's and maternal coping strategies.

Furthermore, t-test has been used to compare the children's mean scores obtained from each coping scale (monitoring/blunting); the children's mean scores obtained from each locus of control approach (internal/external); and the mothers' mean scores obtained from each coping scale (monitoring/blunting). Finally, a multivariate analysis of variance (MANOVA) has been calculated by continuous variables - i.e. the scores obtained from the tools used - in order to verify the effect of the independent variable, which consisted of health condition of the children of the two groups (healthy children and with ALL) on the dependent variables, such as coping style and locus of control. Hence, MANOVA has been used to investigate likely differences between the experimental and control groups with regard to the use of monitoring and blunting coping, and internal and external locus of control.

\section{Results}

The data concerning the coping strategies of children with Leukemia (experimental group), which were obtained from the CBSS, and of their respective mothers', which were obtained from the MBSS, show that both mothers and children resorted to monitoring coping strategies with a statistically significant rate of occurrence (children: $\mathrm{M}=17.8, \mathrm{SD}=3.8$; mothers: $\mathrm{M}=10.48, \mathrm{SD}=3.4$ ), rather than to blunting coping strategies (children: $\mathrm{M}=14.1, \mathrm{SD}=3.7$; mothers: $\mathrm{M}=5.2, \mathrm{SD}=3.5$ ) (as for children: $\mathrm{t}=3.09$; $\mathrm{df}=39 ; \mathrm{P}=0.004$; as for mothers: $\mathrm{t}=9.9$; $\mathrm{df}=39 ; \mathrm{P}=0.001$ ) (Tables 2 and 3). Hence, the adopted coping strategies result to mainly be of active response type rather than of avoidance and/or delegating type. The data from locus of Control Scale for Children concerning the modality of causal attribution to events highlight the children's tendency towards internal causes $(\mathrm{M}=53.1, \mathrm{SD}=4.7)$, which is shown by the statistically significant difference between their internal and external locus of control $(\mathrm{t}=11.7 ; \mathrm{df}=39 ; \mathrm{P}=0.001)$ (Tables 2 and 3 ).

The results gained from the control group

Table 2. Descriptive statistics and multivariate analysis of variance (MANOVA): experimental group (40 children and their mothers) and control group (30 children).

\begin{tabular}{|c|c|c|c|c|}
\hline Variables & $\begin{array}{l}\text { Children experimental group, } \\
\text { mean (SD) }\end{array}$ & $\begin{array}{l}\text { Children control group, } \\
\text { mean (SD) }\end{array}$ & $\begin{array}{l}\text { Mothers experimental group, } \\
\text { mean (SD) }\end{array}$ & MANOVA \\
\hline Coping monitoring & $17.8(3.8)$ & $18.9(3.5)$ & 10. (3.4) & $\begin{array}{c}\mathrm{F}_{(2,69)}=1.62 \\
\text { sign. }>0.05 \\
\eta^{2}=0.023\end{array}$ \\
\hline Coping blunting & $14.1(3.7)$ & $13(3.5)$ & $5.2(3.5)$ & $\begin{array}{c}F_{(2,69)}=1.52 \\
\text { sign. }>0.05 \\
\eta^{2}=0.022\end{array}$ \\
\hline Internal locus of control & $53.2(4.7)$ & $56.2(6)$ & - & $\begin{array}{c}\mathrm{F}_{(2,69)}=5.53 \\
\text { sign. }<0.05 \\
\eta 2=0.07\end{array}$ \\
\hline External locus of control & $39(9.5)$ & $42.5(8.2)$ & - & $\begin{array}{c}\mathrm{F}_{(2,69)}=2.61 \\
\text { sign.>0.05 } \\
\eta^{2}=0.037\end{array}$ \\
\hline
\end{tabular}


are almost equivalent. It appears that the healthy children also resorted mainly to monitoring coping strategies $(\mathrm{M}=18.9, \mathrm{SD}=3.49)$ (Table 2). Moreover, the analysis of the variance has revealed a lack of statistically significant differences between the two groups of children with regard to both monitoring $\left[F(2,69)=1.62, P>0.05, \eta^{2}=0.023\right]$ and blunting coping style $[\mathrm{F}(2,69)=1.52, \quad \mathrm{P}>0.05$, $\left.\eta^{2}=0.022\right]$. As for the locus of control, the children of the control group display a prevailing internal causal attribution $(\mathrm{M}=56.2, \mathrm{SD}=6)$. However, the analysis of the variance highlights a significant difference between the two groups in relation to the internal locus of control $\left[\mathrm{F}(2,69)=5.53, \mathrm{P}<0.05, \eta^{2}=0.07\right]$ that shows a higher score from the control group (Table 2).

Finally, the results concerning the likely correlations between the two variables analyzed in the experimental group, coping and locus of control, show the presence of statistically significant positive correlations between monitoring coping strategies and external locus of control $(r=0.400 ; \mathrm{P}<0.05)$ (Table 4$)$. On the contrary, statistically significant correlations are not revealed between monitoring and blunting coping strategies activated by the children and their mothers (Table 5).

\section{Discussion and Conclusions}

The results show some striking aspects of the treatment-related psychological functioning of the children with ALL and their respective mothers, not only as content but rather as novelties compared to the scientific literature of the field. They underline distinct resources in facing the tumor. It seems that, despite the difficulties and painful experiences brought by both the severity of the disease and its treatment, children tend to react adopting active and combative behavior instead of an avoiding, delegating or negating conduct. Hence, contrary to most literature of the field, that highlights a repressive coping style in children with tumor, especially during the treatment phase, 7,20 this study reveals modalities of facing critical events that have proved to be evolutional resources vital for a good adjustment process. 3,29

It is noteworthy that the results of the variance analysis show no statistically significant difference between the coping strategies used by the experimental group and those adopted by the control group. The tendency towards monitoring coping strategies is evident in both cases. The absence of significant differences show that, whether children are suffering from a disease or not, the cognitive, emotional and social aptitudes peculiar to this phase of child evolutional development, makes children reacting actively, and supports them in feeling powerful at having control. The predominance of the monitoring coping style, as an evolutional resource, appears to be more interesting when speaking of the atypical development of children suffering from ALL, and considering the management of the situational complexity. 30

Adopting monitoring coping strategies, rather than blunting, is ascribable to the children's ability to maintain positive, hopeful and recovery-trusting thoughts despite the awareness of physical and psychological implications brought by the chemotherapy treatment. Furthermore, the peculiarities of the monitoring coping strategies, such as addressing attention to the specific problems and context, coupled with seeking out information about what happened, may allow children to research resources, inside and outside their self, which may be advantageous means to go through the risk condition. The monitoring coping style, then, seems to be a cognitive, emotional, and relational capital to handle the disease at best. As it implies good levels of awareness and acknowledgement of the events brought by the treatment phase, and it supports the compliance, it allows the conversion of the condition of a non-normative evolutional crisis into a real evolutional challenge suited to development. ${ }^{31}$

Equally, the mothers of the children with
ALL involved in the study displayed the tendency to adopt this coping style as well. Besides being a further resource favorable to the therapeutic alliance with medical team, 32 the maternal monitoring approach is also advantageous to children who have at their side caregivers who never make them feeling lonely, or terrified by the difficulties arisen. However, the lack of significant correlations between the children's coping strategies and their respective mothers' does not allow to affirm the presence of a connection at the level of modeling, so mothers' coping style presumably has not great influence in shaping their children's ones. Therefore, in consonance with what suggested by a few model of interpreting the process of adjustment to neoplastic disease, it is possible to hypothesize a multi-directional factors that can affect the coping style of children with ALL during the treatment phase. 14,33 The natural predisposition of children and/or cognitive skills could be one among these. The age range analyzed (10-13 years) implies the predominance of cognitive characteristics, such as the logical reasoning and the systematic approach to problem solving that can foster a coping style focused on problem, on seeking out information, and on attempting to activate the proper behaviors to manage difficulties. The children's own perception of the support given by their parents, by their own friends, and the hospital medical team might

Table 3. Paired samples test (experimental group's children and their mothers).

\begin{tabular}{lccccc} 
& Mean & SD & $\mathrm{t}$ & df & Sig \\
$\begin{array}{lcccc}\text { Pair 1 } \\
\text { Children: monitoring-blunting }\end{array}$ & 3.7 & 7.5 & 3.09 & 39 & 0.004 \\
$\begin{array}{l}\text { Pair 2 } \\
\text { Children: internal locus-external locus }\end{array}$ & 13.92 & 7.4 & 11.7 & 39 & 0.001 \\
\hline $\begin{array}{l}\text { Pair 3 } \\
\text { Mothers: monitoring-blunting }\end{array}$ & 5.3 & 3.3 & 9.9 & 39 & 0.001 \\
\hline
\end{tabular}

Table 4. Experimental group: correlations between children's coping strategies and their locus of control (Pearson correlation Coefficient).

\begin{tabular}{lcc} 
Variables & Coping monitoring & Coping blunting \\
Internal locus of control & 0.121 & -0.137 \\
External locus of control & $0.400^{*}$ & $-0.394^{*}$ \\
\hline$*{ }^{*}<0.05$ & &
\end{tabular}

Table 5. Experimental group: correlations between children's coping strategies and their mother's coping strategies (Pearson correlation Coefficient).

\begin{tabular}{lcc} 
Mothers & Children & \\
& Coping monitoring & Coping blunting \\
Coping monitoring & 0.238 & -0.254 \\
Coping blunting & -0.048 & 0.051 \\
\hline
\end{tabular}

$\mathrm{P}<0.01 ; \mathrm{P}<0.05$ 
be another affecting factor. That is the reason why, in the pediatric oncohematology units involved in the research, there is a team of professionals aimed at providing psychological support to the children and their families. It should also be considered that, according to the literature of the field, as these children undergo the treatment, their adjustment gradually changes over the history of the disease. The high post-diagnosis distress seems to progressively decrease, as if a new-born situational routine would allow the children to think about future rather than about the current sufferance. ${ }^{23,34}$ Actually, no coping strategy is only adaptive or non adaptive, since some coping behaviors can be more or less useful depending on at what step of the disease the children are. Escaping or negating behaviors may be advantageous at bearing the pain provoked by the disclosure of the diagnosis, while, on the contrary, they would be non adaptive when adopted especially during the treatment phase, which requires great efforts. Another factor that could affect the coping style of children with ALL, is the representation they have of the critical events occurring in their own life, and of their relations with them. This representation influences the locus of control.22 The interesting point is that the children involved in the study, besides having a high level of monitoring coping style, mainly resorted to the internal locus of control. It seem that the children would tend to face the treatment-related difficulties with sense of responsibility, reckoning themselves as powerful at fostering or not the success of the outcome of the therapeutic path. It should be noted, however, that even though the group of control displayed the predominance of internal locus of control, the scores obtained by the experimental group are lower. This result can be interpreted in terms of resource advantageous to children with ALL, since an excessive internalization of the locus of control could enhance their sense of guilt and responsibility, which are unhelpful to go through the risk condition.

The correlational data between coping style and locus of control of the children with ALL appear to be interesting since they highlight a significant correlation, which is positive only between the monitoring coping style and the external locus of control. They suggest a thorough examination by increasing the size of the sample. It seems that the externals would tend to face critical events by adopting as active coping strategies as the internals'. Hence, even the children who feel less powerful at controlling the outcomes of events, displayed to be used to resorting to the monitoring coping style, their behavior is active, and they seek out clear information before undergoing the treatment.

Both the children and their mothers showed the tendency to actively cooperate with the medical team, who is required to provide clear information about the characteristics and the probable implications of conventional and non conventional therapies. ${ }^{35}$ The acquired information can guide, control and support them in finding the proper adaptive behaviors, which would be the concept field of reference for the cognitive coping that this study reckons as a field of the utmost importance for the facing strategies. Therefore, the clarity of communication about the value of the treatment, and the adequacy of information provided about both the cancer treatment and the specific therapeutic course planned for the children, may avoid the risk that they would refuse to comply the recommended election treatment, or not cooperate with the medical staff, or stop the treatment and end the relationships with the doctors.

The considerations about the outcomes underline that the active involvement of the children and their parents during the treatment phase would minimize the sense of passivity, and the perception of incapability that often occur together with the emotional heaviness of such a phase. ${ }^{36-38}$

Lastly, the results suggest carrying on the study with an increase of the size of the sample, and new measurements of the likely correlations between the children's coping strategies and further variables relating to the locus of control such as the temperament, distinct cognitive skills, etc.

\section{References}

1. Axia G, ed. Elementi di psico-oncologia pediatrica. Roma: Carocci; 2004.

2. Perricone G, Morales MR, Polizzi C, Fontana V. [Narrative inquiries representations and self-esteem in the child affected by tumor: a pre-test pilot study]. Minerva Pediatr 2010;62:43-50. [Article in Italian].

3. Perricone G, Polizzi C, Morales MR, et al. Functioning of family system in pediatric oncology during treatment phase. Pediatr Hematol Oncol 2012;29:652-62.

4. Perricone G, Prista Guerra M, Cruz 0, et al. Maternal coping strategies in response to a child's chronic and oncological disease: a cross-cultural study in Italy and Portugal. Pediatr 2013;5:43-7.

5. Miller KS, Vannatta K, Compas BE, et al. The role of coping and temperament in the adjustment of children with cancer. $\mathrm{J}$ Pediatr Psychol 2009;34:1135-43.

6. Patenaude AF, Kupst MJ. Psychological functioning in pediatric cancer. J Pediatr Psychol 2005;30:9-27.

7. Phipps S, Steele R. Repressive adaptive style in children with chronic illness.
Psychosom Med 2002;64:34-42.

8. AIRTUM. I tumori in Italia - Rapporto AIRTUM 2012. I Tumori dei bambini e degli adolescenti. Epidemiol Prev 2013;37:1-296.

9. AIRTUM. I tumori in Italia - Rapporto AIRTUM 2013. Tumori multipli. Epidemiol Prev 2013;37:1-152.

10. Merks JH, Ozgen HM, Koster J, et al. Prevalence and patterns of morphological abnormalities in patients with childhood cancer. JAMA 2008;299:61-9.

11. Sourkes BM. Armfuls of time. Pittsburg: University Pittsburg Press; 1995.

12. Saccomani R, ed. AIEOP, Tutti bravi. Psicologia e clinica del bambino portatore di tumore. Milano: Raffaello Cortina; 1998.

13. Van Cleve L, Bossert E, Beecroft P, et al. The pain experience of children with leukemia during the first year after diagnosis. Nurs Res 2004;53:1-10.

14. Grootenhuis MA, Last BF. Adjustment and coping by parents of children with cancer: a review of the literature. Support Care Cancer 1997;5:466-84.

15. Sorgen KE, Manne SL. Coping in children with cancer: examining the goodness of fit hypothesis. Children Health Care 2002;31:191-207.

16. Clerici CA, Ferrari A, Albasi C, et al. Il disagio psichico in pazienti sopravvissuti a neoplasie maligne in età pediatrica; revisione della letteratura ed esperienze cliniche. Abilitazione Riabilitazione 2003;1:71-82.

17. Patterson MJ, Holm KE, Gurney JG. The impact of childhood cancer on the family: a qualitative analysis of strains, resources and coping behaviours. Psychooncology 2004;13:390-407.

18. Hildenbrand AK, Clawson KJ, Alderfer MA, Marsac ML. Coping strategies in parents of children with cancer. Soc Sci Med 2005;60:965-75.

19. Norberg AL, Lindblad F, Boman KK. Coping strategies in parents of children with cancer. Soc Sci Med 2005;60:965-75.

20. Phipps S, Fairclough D, Mulhern RK. Avoidant coping in children with cancer. J Pediatr Psychol 1995;20:217-32.

21. Weisz JR, McCabe MA, Dennig MD. Primary and secondary control among children undergoing medical procedures: adjustment as a function of coping style. $\mathrm{J}$ Consult Clin Psychol 1994;62:324-32.

22. Rotter JB. Generalized expectances for internal versus external control of reinforcement. Psychol Monogr 1966;80:1-28.

23. Sawyer M, Antoniou G, Toogood I, et al. Childhood cancer: a 4 year prospective study of the psychological adjustment of children and parents. J Pediatr Hematol Oncol 2000;22:214-20.

24. Odero S, Clerici CA, Ripamonti C. Clinical considerations and coping assessment in 
pediatric oncology: a literature review. Ricerche di Psicologia 2005;4:81-108.

25. SIOP. Atti del XXXXI Congresso Mondiale Società Internazionale di Oncologia Pediatrica, San Paolo, Brasile. Pediatr Blood Cancer 2009:701-915.

26. Miller SM. Monitoring and blunting styles of coping with cancer influence the information patients want and need about their disease. Cancer 1995;76:167-76.

27. Miller SM. Monitoring and blunting: validation of a questionnaire to assess styles of information seeking under threat. J Pers Soc Psychol 1987;52:345-53.

28. Nowicki S, Strickland BR. A locus of control scale. J Consult Clin Psychol 1973;40:148-54.

29. Scrimin S, Axia V. Processi di adattamento alla malattia tumorale in età pediatrica. In: Axia V, ed. Elementi di psico-oncologia pediatrica. Roma: Carocci; 2004.

30. Klassen AF, Klaassen R, Dix D, et al.
Impact of caring for a child with cancer on parents' health-related quality of life. J Clin Oncol 2008:5884-9.

31. Baltes PB, Reese HW, Lipsitt LP. Life-span developmental psychology. Ann Rev Psychol 1980;31:65-110.

32. Masera G, Spinetta JJ, Jankovic M, et al. Guidelines for a therapeutic alliance between families and staff: a report of the SIOP Working Committee on psychosocial issues in pediatric oncology. Med Pediatr Oncol 1998;30:183-6.

33. Wijnberg-Williams BJ, Kamps WA, Klip EC, Hoekstra-Weebers JE. Psychological adjustment of pediatric cancer patients revisited: five years later. Psychooncology 2005;15:1-8.

34. Tyc VL, Mulhern RK, Jayawardene D, Fairclough D. Chemotherapy induced nausea and emesis in pediatric cancer patient: an analysis of coping strategies. $\mathrm{J}$ Pain Symptom Manage 1995;10:338-47.
35. Stewart JL, Pyke-Grimm KA, Patterson Kelly K. Parental treatment decision making in pediatric oncology. Semin Oncol Nurs 2005;21:89-97.

36. Spinetta JJ, Masera G, Eden T, et al. Refusal, non-compliance, and abandonment of treatment in children and adolescents with cancer. A report of the SIOP working committee on psychosocial issues in pediatric oncology. Med Pediatr Oncol 2002;38:114-7.

37. Meyler E, Guerin S, Kiernan G, Breatnach F. Review of family-based psychosocial interventions for childhood cancer. J Pediatr Psychol 2010;35:1116-32.

38. Perricone G, Polizzi C, Morales MR, Fontana V. Perception of family functioning and coping strategies in mothers of children suffering from tumour during the treatment phase. Psicologia della Salute 2013;3:101-13. 